\title{
Impact of Phenazine-1-carboxylic acid upon Biofilm Development in the Rhizosphere of Dryland and Irrigated Wheat.
}

\author{
Melissa K. LeTourneau ${ }^{1}$, Matthew M. Marshall ${ }^{2}$, Linda S. Thomashow ${ }^{3}$, and James B. Harsh ${ }^{1}$ \\ 1. Department of Crop and Soil Sciences, Washington State University, Pullman, WA, USA. \\ 2. Pacific Northwest National Laboratory, United States Department of Energy, Richland, WA, USA. \\ 3. Agricultural Research Service, United States Department of Agriculture, Pullman, WA, USA.
}

Rhizobacterial biofilms are important sinks for plant-derived carbon and sources of organic matter in soil. Phenazine-1-carboxylic acid (PCA), a bacterial metabolite that has been shown to promote biofilm development via reduction of iron in culture [1], has been observed in concentrations up to $1 \mu \mathrm{g} / \mathrm{g}$ root in the rhizospheres of dryland, but not irrigated, cereal monocultures throughout the low-precipitation zone of the Columbia Plateau [2]. Because soils in this area are particularly susceptible to loss of organic matter and erosion due to widespread, long-term conventional tillage practices, we are investigating the impact of PCA upon storage of plant-derived carbon in rhizobacterial biofilms under both dryland and irrigated conditions. We hypothesize that PCA promotes accumulation of extracellular polymeric substances (EPS) in the rhizosphere, especially under dryland conditions.

Our approach involves microscopic comparisons of biofilms formed by a PCA-producing fluorescent pseudomonad strain $\left(\mathrm{PCA}^{+}\right)$and an isogenic mutant impaired in PCA synthesis $\left(\mathrm{PCA}^{-}\right)$grown on wheat roots. In order to simulate dryland and irrigated soil moisture conditions, the wheat is planted in soilfilled columns within a growth chamber imposing temperature, humidity, and soil-moisture controls. We are comparing root-colonization patterns using confocal microscopy, extent and morphology of biofilm matrices using focused-ion-beam SEM, and nano-structural characteristics of biofilm matrices using helium-ion microscopy. Non-inoculated controls have been established in these experiments to account for endophytic bacteria introduced from the seed and bulk soil bacteria that have survived soil autoclaving.

The soil-grown root systems in our experiments have robust rhizo-sheaths (Figure 1), such that representative colonies are easier to identify on roots grown on filter paper (Figure 2). However, we have observed some consistent colony morphologies on soil-grown root surfaces, (Figure 3). Additional sample comparisons using the variety of imaging techniques described above are expected to confirm that the $\mathrm{PCA}^{+}$strain consistently produces more EPS than the $\mathrm{PCA}^{-}$strain under dryland and irrigated conditions [3].

References:

[1] Y Wang, JC Wilks, T Danhorn, et al., J. Bacteriol. 193 (2011), p. 3606.

[2] DV Mavrodi, O Mavrodi, JA Parejko, et al., Appl. Environ. Microbiol. 78 (2012), p. 804.

[3] The authors acknowledge funding from the USDA Agriculture and Food Research Initiative grant 2011-67019-30212, the DOE Office of Science Graduate Student Research Program, and the Otto and Doris Amen Dryland Research Endowment. We also appreciate the consultation, training, and analyses provided by microscopy and spectroscopy scientists at the DOE Environmental Molecular Sciences Laboratory, and staff at the Franceschi Microscopy and Imaging Center at Washington State University. 


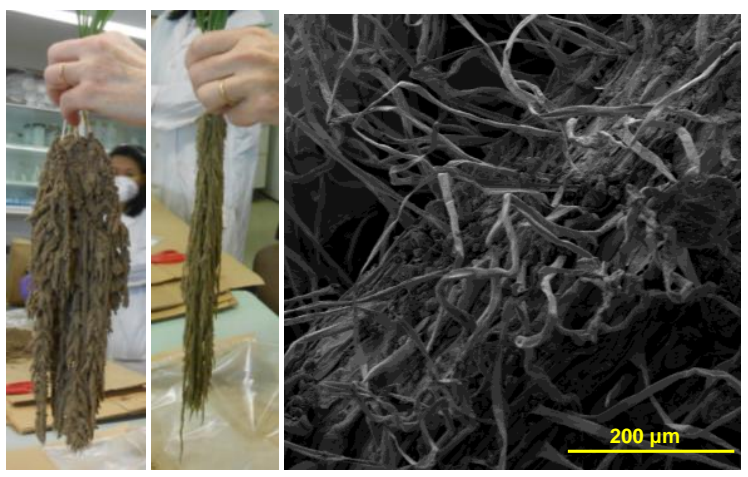

Figure 1. Soil-grown roots from the growth chamber experiments have robust rhizo-sheaths, which complicate identification of representative colonies at root surfaces.
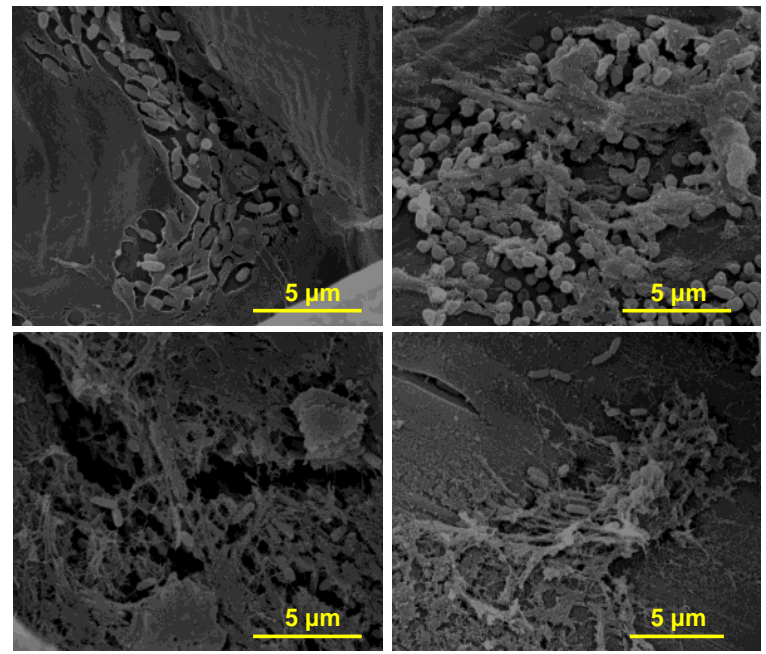

Figure 2. Representative colony morphologies on roots grown on filter paper. Upper images are $\mathrm{PCA}^{+}$ colonies, while lower images are $\mathrm{PCA}^{-}$colonies. More sample comparisons are required to determine whether these distinct colony morphologies are consistent.

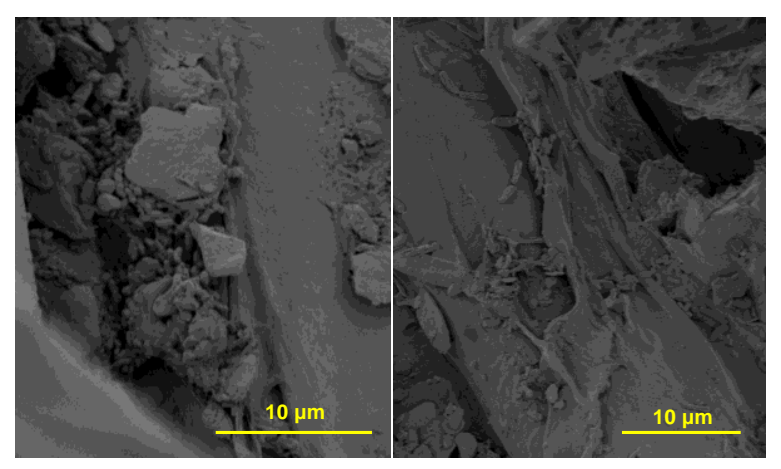

Figure 3. Colonies on soil-grown roots. The left image is a $\mathrm{PCA}^{+}$colony, while the right image is a $\mathrm{PCA}^{-}$colony. Larger bacteria in the $\mathrm{PCA}^{-}$colony are most likely endophytes introduced from the seed, or bulk soil bacteria that survived soil autoclaving. 